\title{
BMJ Open Single-dose intra-articular bupivacaine plus morphine after knee arthroscopic surgery: a meta-analysis of randomised placebo-controlled studies
}

\author{
Yi-lun Wang, ${ }^{1}$ Chao Zeng, ${ }^{1}$ Dong-xing Xie, ${ }^{1}$ Ye Yang, ${ }^{1}$ Jie Wei, ${ }^{2}$ Tuo Yang, ${ }^{1}$ \\ Hui Li, ${ }^{1}$ Guang-hua Lei ${ }^{1}$
}

To cite: Wang Y-lun, Zeng C, Xie D-xing, et al. Single-dose intra-articular bupivacaine plus morphine after knee arthroscopic surgery: a metaanalysis of randomised placebo-controlled studies. BMJ Open 2015;5:e006815. doi:10.1136/bmjopen-2014006815

- Prepublication history for this paper is available online. To view these files please visit the journal online (http://dx.doi.org/10.1136/ bmjopen-2014-006815).

Y-IW and CZ contributed equally.

Received 3 October 2014 Revised 5 May 2015 Accepted 7 May 2015

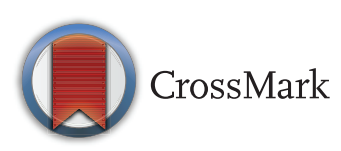

${ }^{1}$ Department of Orthopaedics, Xiangya Hospital, Central South University, Changsha, Hunan Province, China ${ }^{2}$ Department of Epidemiology and Health Statistics, School of Public Health, Central South University, Changsha, Hunan Province, China

Correspondence to Dr Guang-hua Lei; Igh9640@sina.cn

\section{ABSTRACT}

Objectives: To evaluate the efficacy and safety of single-dose intra-articular bupivacaine plus morphine after knee arthroscopic surgery.

Design: Meta-analysis.

Data sources and study eligibility criteria:

A comprehensive literature search, using Medline (1966-2014), the Cochrane Central Register of Controlled Trials and Embase databases, was conducted to identify randomised placebo-controlled trials that used a combination of single-dose intra-articular bupivacaine and morphine for postoperative pain relief.

Results: 12 articles were included in this metaanalysis. The mean visual analogue scale (VAS) scores of the bupivacaine plus morphine group were significantly lower than those of the placebo group (weighted mean difference (WMD) $-1.75 ; 95 \% \mathrm{Cl}$ -2.16 to $-1.33 ; p<0.001)$. The VAS scores at the last follow-up time point (last VAS scores) of the bupivacaine plus morphine group were also significantly lower than those of the placebo group (WMD $-1.46 ; 95 \% \mathrm{Cl}-1.63$ to $-1.29 ; p<0.001$ ). The number of patients requiring supplementary analgesia was also significantly reduced (RR $0.60 ; 95 \% \mathrm{Cl} 0.39$ to $0.93 ; p=0.02$ ), while there was no significant difference in the time to first analgesic request (WMD $3.46 ; 95 \% \mathrm{Cl}-1.81$ to $8.72 ; \mathrm{p}=0.20$ ) or short-term side effects (RR 1.67; $95 \% \mathrm{Cl} 0.65$ to $4.26 ; p=0.29$ ).

Conclusions: The administration of single-dose intraarticular bupivacaine plus morphine after knee arthroscopic surgery is effective for pain relief, and its short-term side effects remain similar to saline placebo.

\section{INTRODUCTION}

Knee arthroscopic surgery is a very common surgical procedure that usually does not require hospitalisation before or after surgery. In spite of its popularity, this type of surgery can sometimes cause severe pain. ${ }^{1}$ Solheim $e t a l^{2}$ reported that around $60 \%$ of patients may experience moderate to severe

\section{Strengths and limitations of this study}

- This is the first quantitative analysis to compare single-dose intra-articular (IA) bupivacaine plus morphine with saline placebo after knee arthroscopic surgery.

- All included studies in this meta-analysis adopted a randomised placebo-controlled design.

- A comprehensive report on the effects of singledose IA bupivacaine plus morphine after knee arthroscopic surgery is provided.

- Substantial heterogeneity was observed in the number of patients requiring supplementary analgesia and the time to first analgesic request.

- None of the observation periods of the included studies were long enough to detect cartilage toxicity.

pain after knee arthroscopic surgery, which can delay rehabilitation and increase the risk of postoperative complications. Therefore, adequate postoperative pain control is essential and can improve postoperative convalescence.

The use of intra-articular (IA) anaesthesia after arthroscopic knee surgery became popular after a seminal publication by Stein et $a \vec{l}^{3}$ in 1991. Currently, bupivacaine as a local anaesthetic and morphine to relieve pain are widely used in combination to provide effective postoperative analgesia. ${ }^{4-10}$ However, the efficacy and safety of this combination for patients undergoing knee arthroscopic surgery remains controversial. Some studies found that IA bupivacaine plus morphine provided effective pain relief for patients, ${ }^{11-19}$ while others did not. ${ }^{20-22}$ Consequently, this quantitative meta-analysis involving 12 randomised placebo-controlled trials (RCTs) was designed to examine the efficacy and safety of IA bupivacaine in combination with morphine for patients undergoing knee arthroscopic surgery. 
Figure 1 Flow diagram of screened, excluded and analysed articles.

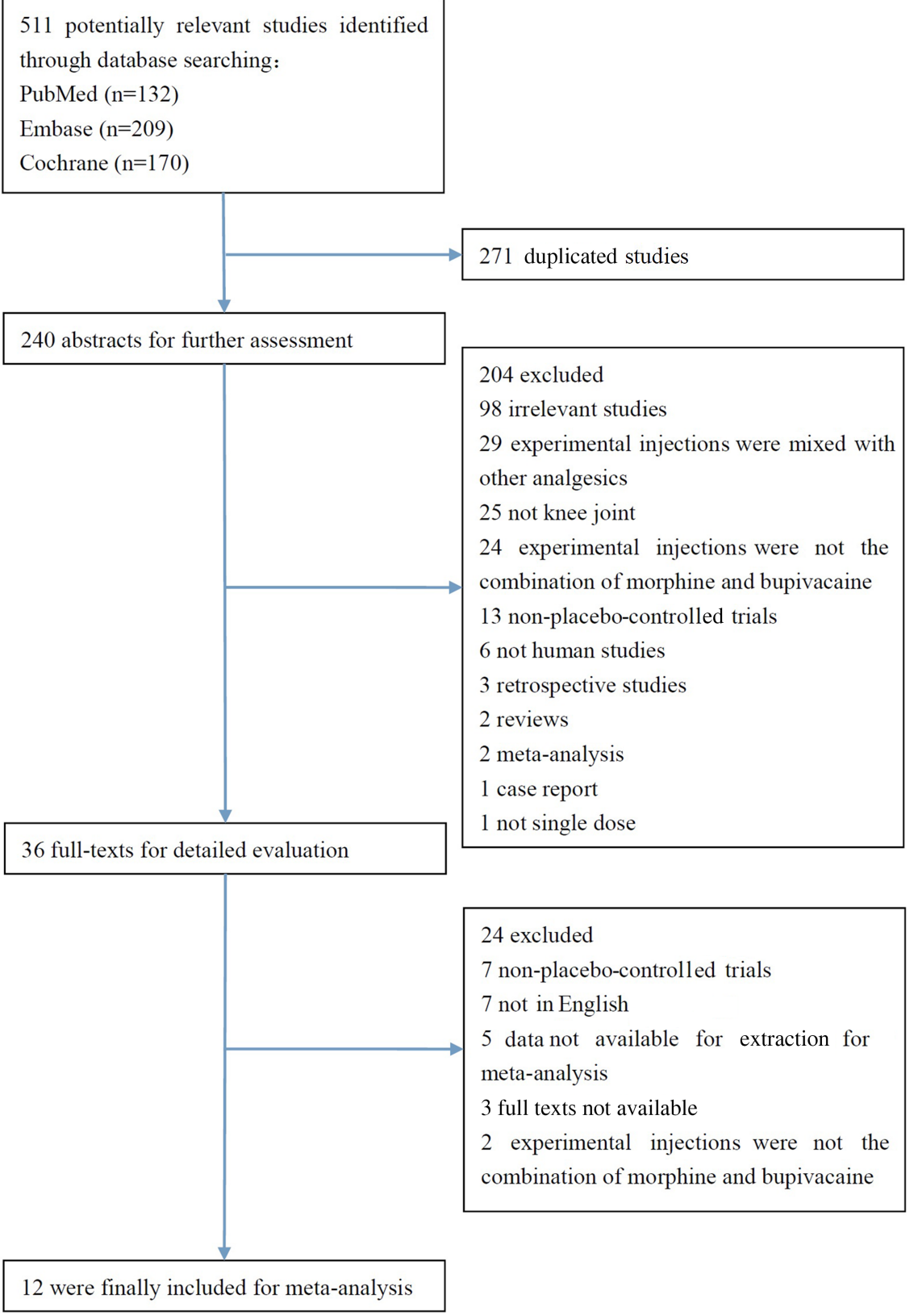

\section{MATERIALS AND METHODS} Search strategy

This meta-analysis was performed in accordance with the PRISMA guidelines. ${ }^{23}$ PubMed/Medline (19662014), the Cochrane Central Register of Controlled Trials (CENTRAL) and Embase databases were searched for relevant studies comparing bupivacaine plus morphine with placebo in patients receiving a single-dose IA injection after knee arthroscopic surgery. Search terms were 'arthroscopy', 'arthroscopic', 'arthroscope', 'morphine', 'bupivacaine' and 'randomised controlled trials'. No restrictions were imposed. The references and reviews of the retrieved studies were also assessed.

\section{Study selection}

The citations and abstracts generated by the literature search were reviewed by two researchers independently.
Inclusion criteria were as follows: (a) patients undergoing knee arthroscopic surgery; (b) administration of combination therapy of single-dose IA bupivacaine and morphine for postoperative pain relief; (c) RCTs; and (d) administration of saline in the control group. Exclusion criteria were as follows: (a) non-RCTs; (b) non-placebo-controlled trials; (c) the combination therapy of single-dose IA bupivacaine and morphine not administered in the experimental group; (d) data not available for extraction; and (e) unavailability of the full text.

\section{Data extraction}

The two independent researchers used Review Manager V.5.2 software (RevMan V.5.2; The Cochrane Collaboration, Oxford, UK) to record and manage information. The SD of outcome, if not reported, was estimated based on sample size, the SE or the $95 \%$ CI. Data were also extracted from figures by using GetData V.2.20 


\begin{tabular}{|c|c|c|c|c|c|c|c|c|c|c|c|c|}
\hline Study & Year & $\begin{array}{l}\text { Age } \\
\text { (mean) }\end{array}$ & $\begin{array}{l}\text { Sex } \\
\text { (male/female) }\end{array}$ & $n$ (B-M/C) & $\begin{array}{l}\text { Doses } \\
(\mathrm{B}, \mathrm{M})(\mathrm{mg})\end{array}$ & Concentration & $\begin{array}{l}\text { Time of } \\
\text { follow-up (h) }\end{array}$ & $\begin{array}{l}\text { Type of } \\
\text { anaesthesia }\end{array}$ & Epinephrine & Type of surgery & $\begin{array}{l}\text { Time of intra-articular } \\
\text { injection }\end{array}$ & MOS \\
\hline Hosseini et al ${ }^{11}$ & 2012 & 25.2 & $40 / 0$ & $20 / 20$ & 100,10 & $0.5 \%$ & $\begin{array}{l}0,0.5,1,1.5 \\
2,4,6,12 \\
24\end{array}$ & General & No & $\begin{array}{l}\text { Arthroscopic ACL } \\
\text { reconstruction }\end{array}$ & $\begin{array}{l}10 \mathrm{~min} \text { before the } \\
\text { release of the tourniquet }\end{array}$ & 5 \\
\hline Danieli et $a l^{2}$ & 2012 & 32.8 & $29 / 1$ & $15 / 15$ & 50,1 & $0.25 \%$ & $6,24,48$ & Spinal & No & $\begin{array}{l}\text { Videoarthroscopy-assisted } \\
\text { ACL reconstruction }\end{array}$ & $\begin{array}{l}\text { At the end of } \\
\text { arthroscopic surgery }\end{array}$ & 6 \\
\hline Goodwin et $a l^{13}$ & 2005 & 32.6 & $14 / 4$ & $10 / 8$ & 150,1 & $0.25 \%$ & $0,1,2$ & General & Yes & $\begin{array}{l}\text { Arthroscopic surgery without } \\
\text { concomitant ligamentous } \\
\text { reconstruction }\end{array}$ & $\begin{array}{l}\text { At the end of } \\
\text { arthroscopic surgery }\end{array}$ & 5 \\
\hline Tetzlaff et a $\left.\right|^{14}$ & 1999 & NA & NA & $10 / 10$ & 150,1 & 0.25 & $\begin{array}{l}0.5,1,1.5,2 \\
4, \text { average }\end{array}$ & General & Yes & $\begin{array}{l}\text { Arthroscopic } A C L \\
\text { reconstruction }\end{array}$ & $20 \mathrm{~min}$ before incisions & 4 \\
\hline De Andres et $a l^{16}$ & 1998 & 33.3 & $29 / 22$ & $26 / 25$ & 50,1 & $0.25 \%$ & $\begin{array}{l}0.33,4,10 \\
16,24\end{array}$ & General & No & Arthroscopic meniscectomy & $\begin{array}{l}\text { At the end of } \\
\text { arthroscopic surgery }\end{array}$ & 6 \\
\hline Gatt et $a l^{15}$ & 1998 & NA & NA & $10 / 10$ & 150,1 & $0.25 \%$ & $\begin{array}{l}0,0.5,1,1.5 \\
2\end{array}$ & General & Yes & $\begin{array}{l}\text { Arthroscopic ACL } \\
\text { reconstruction }\end{array}$ & $\begin{array}{l}\text { At the end of } \\
\text { arthroscopic surgery }\end{array}$ & 5 \\
\hline Denti et al (group A) ${ }^{20}$ & 1997 & NA & NA & $11 / 12$ & 50,2 & $0.25 \%$ & $\begin{array}{l}1,3,6,12 \\
24\end{array}$ & Spinal & No & Operative knee arthroscopy & $\begin{array}{l}10 \mathrm{~min} \text { before the } \\
\text { release of the tourniquet }\end{array}$ & 5 \\
\hline Denti et al (group B) ${ }^{20}$ & 1997 & NA & NA & $10 / 10$ & 50,2 & $0.25 \%$ & $\begin{array}{l}1,3,6,12 \\
24\end{array}$ & General & No & $\begin{array}{l}\text { Arthroscopic ACL } \\
\text { reconstruction }\end{array}$ & $\begin{array}{l}10 \mathrm{~min} \text { before the } \\
\text { release of the tourniquet }\end{array}$ & 5 \\
\hline Aasbo et $a^{P^{1}}$ & 1996 & 41 & $33 / 21$ & $27 / 27$ & 50,3 & $0.25 \%$ & $\begin{array}{l}1,2,3,4,8 \\
12,24,72 \\
168\end{array}$ & General & No & Arthroscopic surgery & $\begin{array}{l}8 \mathrm{~min} \text { before the release } \\
\text { of the tourniquet }\end{array}$ & 5 \\
\hline Brandsson et al ${ }^{17}$ & 1996 & NA & NA & $20 / 20$ & 75,1 & $0.375 \%$ & $\begin{array}{l}1,2,4,6,24 \\
48\end{array}$ & General & No & $\begin{array}{l}\text { Arthroscopic ACL } \\
\text { reconstruction }\end{array}$ & $\begin{array}{l}\text { At the end of } \\
\text { arthroscopic surgery }\end{array}$ & 5 \\
\hline Karlsson et al ${ }^{18}$ & 1995 & NA & NA & $10 / 10$ & 75,1 & $0.375 \%$ & $\begin{array}{l}2,4,6,24 \\
48\end{array}$ & General & No & $\begin{array}{l}\text { Arthroscopic ACL } \\
\text { reconstruction }\end{array}$ & $\begin{array}{l}\text { At the end of } \\
\text { arthroscopic surgery }\end{array}$ & 5 \\
\hline Bjornsson et $a^{P^{2}}$ & 1994 & 34 & $30 / 8$ & $19 / 19$ & $47.5,1$ & $0.25 \%$ & $\begin{array}{l}0,0.5,1,1.5 \\
2,8,24,48\end{array}$ & General & No & Arthroscopic surgery & $\begin{array}{l}5-10 \mathrm{~min} \text { before the } \\
\text { release of the tourniquet }\end{array}$ & 4 \\
\hline Joshi et $a l^{19}$ & 1993 & 31.2 & $14 / 6$ & $10 / 10$ & $62.5,5$ & $0.25 \%$ & $1,2,4,8,24$ & General & No & $\begin{array}{l}\text { Diagnostic arthroscopies, } \\
\text { arthroscopic meniscectomy }\end{array}$ & $\begin{array}{l}10 \mathrm{~min} \text { before the } \\
\text { release of the tourniquet }\end{array}$ & 4 \\
\hline
\end{tabular}


Table 2 Modified Oxford scores of the included studies

\begin{tabular}{|c|c|c|c|c|c|}
\hline Studies & $\begin{array}{l}\text { Randomised } \\
\text { method }\end{array}$ & $\begin{array}{l}\text { Concealment } \\
\text { allocation }\end{array}$ & Blinding & Follow-up & $\begin{array}{l}\text { Total } \\
\text { score }\end{array}$ \\
\hline Hosseini et al ${ }^{11}$ & 2 & 1 & 2 & 0 & 5 \\
\hline Danieli et al ${ }^{12}$ & 1 & 2 & 2 & 1 & 6 \\
\hline Goodwin et $a l^{13}$ & 1 & 1 & 2 & 1 & 5 \\
\hline Tetzlaff et al ${ }^{14}$ & 1 & 2 & 1 & 0 & 4 \\
\hline De Andres et $a l^{16}$ & 2 & 2 & 2 & 0 & 6 \\
\hline Gatt et $a l^{15}$ & 1 & 1 & 2 & 1 & 5 \\
\hline Denti et $a^{\text {PO }}$ & 2 & 1 & 1 & 1 & 5 \\
\hline Aasbo et $a^{p^{1}}$ & 1 & 1 & 2 & 1 & 5 \\
\hline Brandsson et al ${ }^{17}$ & 1 & 1 & 2 & 1 & 5 \\
\hline Karlsson et $a l^{18}$ & 1 & 2 & 1 & 1 & 5 \\
\hline Bjornsson et $a^{22}$ & 1 & 1 & 1 & 1 & 4 \\
\hline Joshi et al ${ }^{19}$ & 1 & 1 & 1 & 1 & 4 \\
\hline
\end{tabular}

software. If there were more than two experimental groups in one study, data were extracted only for the bupivacaine plus morphine group and the placebo group.

The basic information extracted from the studies included: first author, year of publication, mean age, sex ratio, number of patients in the experimental and control groups, doses of bupivacaine and morphine, concentration of bupivacaine, follow-up time points, type of anaesthesia, epinephrine used, type of surgery, IA injection time, and modified Oxford scores (MOS). ${ }^{24} 25$ MOS was assessed by the two independent researchers and used to measure the quality of each study according to the method of randomisation, concealment allocation, blinding and follow-up. Any disagreements between the two researchers were resolved by discussion.

The primary outcomes of interest were pain intensity, which was assessed on a visual analogue scale (VAS), and side effects. The secondary outcomes were the number of patients requiring supplementary analgesia and the time to first request for analgesia.
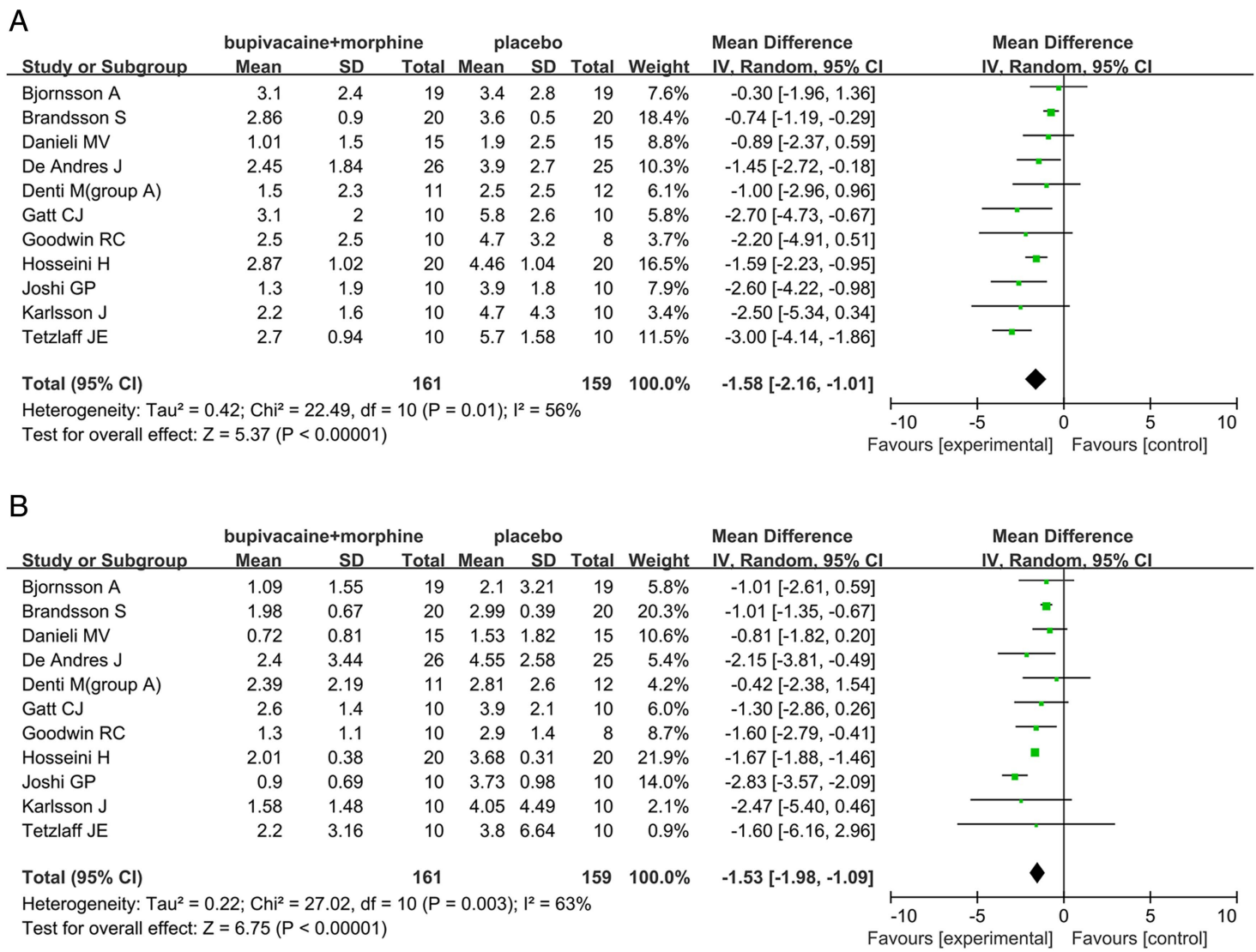

Figure 2 (A) Forest plot of mean VAS scores of postoperative pain intensity (0-10 points). (B) Forest plot of last VAS scores of postoperative pain intensity (0-10 points). 
Table 3 Results of sensitivity analyses

\begin{tabular}{|c|c|c|c|c|}
\hline \multirow[b]{2}{*}{ Reason for exclusion of studies } & \multicolumn{2}{|l|}{$\begin{array}{l}\text { Pooled results of } \\
\text { the remaining studies }\end{array}$} & \multicolumn{2}{|c|}{$\begin{array}{l}\text { Heterogeneity of } \\
\text { the remaining studies }\end{array}$} \\
\hline & WMD/RR & p Value & $I^{2}(\%)$ & p Value \\
\hline \multicolumn{5}{|l|}{ Mean VAS scores } \\
\hline Treated with a cooling system & $-1.75(-2.16$ to -1.33$)$ & $<0.001$ & 26 & 0.21 \\
\hline Mixed with epinephrine & $-1.10(-1.42$ to -0.77$)$ & $<0.001$ & 31 & 0.18 \\
\hline Spinal anaesthesia & $-1.72(-2.39$ to -1.05$)$ & $<0.001$ & 64 & 0.005 \\
\hline Small sample size (less than 10 in control group) & $-1.56(-2.16$ to -0.96$)$ & $<0.001$ & 59 & 0.009 \\
\hline Mild pain score in control group (mean VAS value $\leq 3$ ) & $-1.72(-2.39$ to -1.05$)$ & $<0.001$ & 64 & 0.005 \\
\hline \multicolumn{5}{|l|}{ Last VAS scores } \\
\hline Treated with a cooling system & $-1.70(-1.89$ to -1.50$)$ & $<0.001$ & 41 & 0.09 \\
\hline Mixed with epinephrine & $-1.54(-2.06$ to -1.01$)$ & $<0.001$ & 74 & 0.0003 \\
\hline Spinal anaesthesia & $-1.68(-2.16$ to -1.19$)$ & $<0.001$ & 66 & 0.003 \\
\hline Small sample size (less than 10 in control group) & $-1.52(-2.01$ to -1.04$)$ & $<0.001$ & 67 & 0.001 \\
\hline Mild pain score in control group (mean VAS value $\leq 3$ ) & $-1.76(-1.96$ to -1.56$)$ & $<0.001$ & 47 & 0.09 \\
\hline \multicolumn{5}{|l|}{ Number of patients requiring supplementary analgesia } \\
\hline Mixed with epinephrine & $0.66(0.43$ to 1.02$)$ & 0.06 & 61 & 0.02 \\
\hline Spinal anaesthesia & $0.62(0.41$ to 0.95$)$ & 0.03 & 66 & 0.007 \\
\hline
\end{tabular}

\section{Statistical analyses}

Quantitative analysis was performed for pain intensity reported using a VAS, and the time to first request for analgesia. We calculated weighted mean differences (WMDs) and their corresponding 95\% CIs. Dichotomous data on side effects and number of patients requiring supplementary analgesia were summarised using risk ratios (RRs) and their corresponding 95\% CIs. Bupivacaine and morphine were used in different doses, and pain intensity was reported at different follow-up time points in the various studies. In order to facilitate and standardise pooling of data, each group was regarded as a single study, and we computed the mean and SD of mean VAS scores across the different time points of each study. We also analysed the VAS scores at the last follow-up time point (last VAS scores). All VAS scores were converted to a scale ranging from 0 to 10 .

The homogeneity of effect size across trials was tested with the $Q$ statistic $(p \leq 0.05$ was considered heterogeneous). If there was significant heterogeneity among studies, the random-effects model was used; otherwise, the fixed-effects model was employed. We also examined the $\mathrm{I}^{2}$ statistic, which measures the percentage of the total variation across studies which results from heterogeneity rather than chance $\left(\mathrm{I}^{2} \geq 50 \%\right.$ was considered moderately or very heterogeneous). A sensitivity analysis was conducted to examine the influence of various exclusion criteria on overall effect sizes.

Begg's tests ${ }^{26}$ and funnel plots were used to assess publication bias. We used RevMan V.5.2 and STATA V.12.0 (StataCorp LP, College Station, Texas, USA) to perform statistical analyses. $\mathrm{p}<0.05$ was considered to be statistically significant, unless otherwise stated.

\section{RESULTS}

The search strategy identified 511 articles, the full texts of 36 of which were assessed. Eventually, 12 articles ${ }^{11-22}$ were included in the meta-analysis (figure 1). The characteristics of these 12 studies are given in table 1 , and the MOS of each study are listed in table 2.

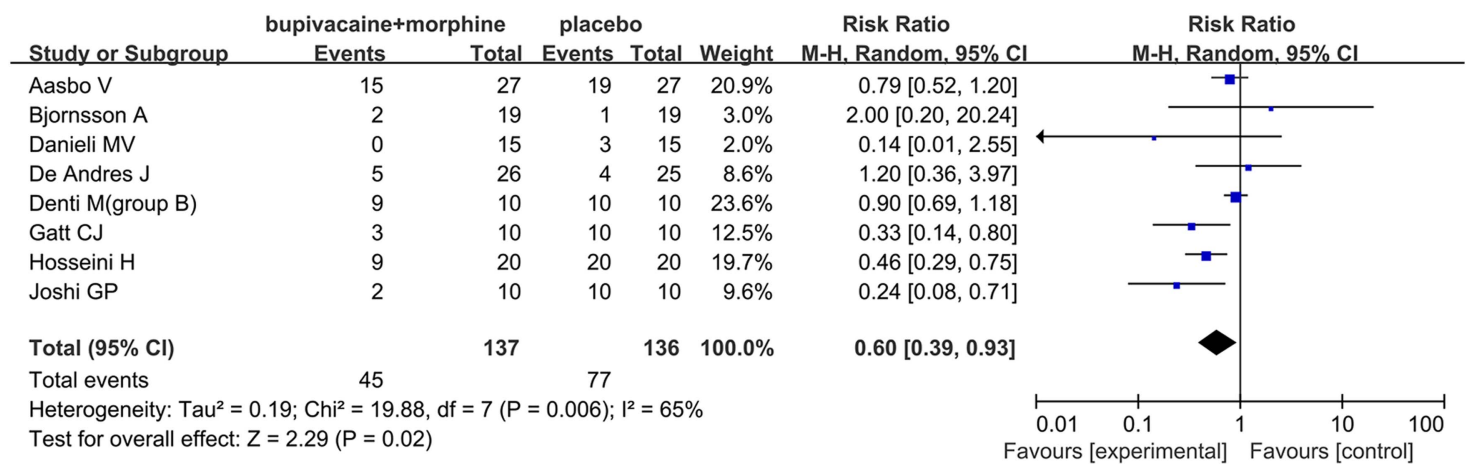

Figure 3 Funnel plots with relative ratios or WMDs of all studies comparing single-dose intra-articular bupivacaine-morphine with placebo. The vertical axis represents effect value, and the abscissa represents the SE of the effect value. The horizontal line in the middle of the funnel plot represents a comprehensive effect value; the two diagonal lines represent the $95 \%$ Cls for a given $\mathrm{SE}$. RR, relative risk; VAS, visual analogue scale; WMD, weighted mean difference. 


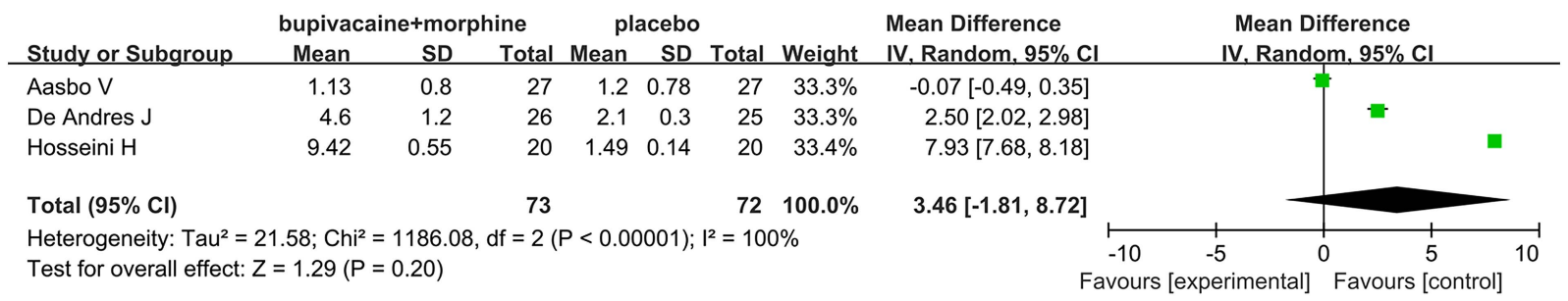

Figure 4 Forest plot of number of patients requiring supplementary analgesia.

\section{VAS values}

All 12 included articles ${ }^{11-22}$ reported pain intensity using VAS scores, but one ${ }^{21}$ only reported the mean VAS score values. Therefore, 11 studies $^{1-20} 22$ involving 320 patients were eligible for assessment of postoperative pain intensity. The bupivacaine plus morphine group demonstrated significantly lower mean VAS scores (WMD $-1.58 ; 95 \% \mathrm{CI}-2.16$ to $-1.01 ; \mathrm{p}<0.001$ ) and last VAS scores (WMD $-1.53 ; 95 \%$ CI -1.98 to -1.09 ; $\mathrm{p}<0.001)$ compared to the placebo group. Substantial heterogeneity was observed in both mean VAS scores $\left(\mathrm{I}^{2}=56 \% ; \mathrm{p}=0.01\right)$ and last VAS scores $\left(\mathrm{I}^{2}=63 \% ; \mathrm{p}=0.003\right)$. The results are shown in figure 2A, B.

Sensitivity analysis explored the potential sources of heterogeneity between the bupivacaine plus morphine group and the placebo group and investigated the influence of various exclusion criteria on the overall risk estimate. The results are presented in table 3. The overall WMD of mean VAS scores did not vary substantially with the exclusion of any single study, and ranged from -1.15 (95\% CI -1.47 to -0.83$)$ to -1.75 (95\% CI -2.16 to $-1.33)$. The overall WMD of last VAS scores did not vary substantially with the exclusion of any single study either, and ranged from -1.46 (95\% CI -1.63 to -1.29 ; $\mathrm{p}<0.001)$ to $-1.70(95 \% \mathrm{CI}-1.89$ to $-1.50 ; \mathrm{p}<0.001)$. In addition, the substantial heterogeneity in mean VAS scores was materially changed by excluding Brandsson's study $\left(I^{2}=26 \% ; p=0.21\right)^{17}$ and Tetzlaff's study $\left(I^{2}=31 \%\right.$; $\mathrm{p}=0.16),{ }^{14}$ while the substantial heterogeneity in last VAS scores was also materially changed by excluding Joshi's study $\left(\mathrm{I}^{2}=38 \% ; \quad \mathrm{p}=0.10\right)^{19}$ and Brandsson's study $\left(\mathrm{I}^{2}=41 \% ; \mathrm{p}=0.09\right) .{ }^{17}$ In order to facilitate and standardise data pooling, the results (mean VAS scores: WMD -1.75 ; $95 \%$ CI -2.16 to $-1.33 ; \mathrm{p}<0.001 ; \mathrm{I}^{2}=26 \%, \mathrm{p}=0.21$; last VAS scores: WMD $-1.46 ; 95 \%$ CI -1.63 to -1.29 ; $\left.\mathrm{p}<0.001 ; \quad \mathrm{I}^{2}=38 \%, \quad \mathrm{p}=0.10\right) \quad$ obtained after excluding Brandsson's and Joshi's articles, respectively, were considered the final results. A Begg's funnel plot did not show any substantial asymmetry (figure 3), and Begg's rank correlation test did not indicate publication bias among the included studies (mean VAS scores: $\mathrm{p}=0.755$; last VAS scores: $\mathrm{p}=1.000$ ).

Number of patients requiring supplementary analgesia Eight articles ${ }^{11} 121516$ 19-22 reported the number of patients who required supplementary analgesia. This number was significantly lower in the bupivacaine plus morphine group than in the placebo group (RR 0.60; $95 \%$ CI 0.39 to 0.93 ; $\mathrm{p}=0.02)$. Substantial heterogeneity was observed $\left(\mathrm{I}^{2}=65 \%\right.$; $\mathrm{p}=0.02$ ). The results are shown in figure 4 .

Sensitivity analysis showed inconsistency in the results (table 3). There was no significant difference in the results (RR $0.66 ; 95 \%$ CI 0.43 to $1.02 ; \mathrm{p}=0.06$ ) after excluding one study ${ }^{15}$ where treatment also included epinephrine. Further exclusion of single studies indicated that the overall RR only changed substantially when the study by Hosseini et $a l^{11}$ was excluded (RR $0.64 ; 95 \%$ CI 0.39 to $1.05 ; \mathrm{p}=0.08$ ). Begg's funnel plot did not show any substantial asymmetry, and Begg's rank correlation test did not indicate publication bias among the included studies $(\mathrm{p}=0.902)$.

\section{Time to first analgesic request}

Three articles ${ }^{11} 1621$ reported the time interval until the first request for additional analgesia. The combined data suggested no significant difference (WMD 3.46; 95\% CI -1.81 to $8.72 ; \mathrm{p}=0.20$ ) between the bupivacaine plus morphine group and the placebo group. Great heterogeneity $\left(\mathrm{I}^{2}=100 \% ; \mathrm{p}<0.001\right)$ was observed. The results are presented in figure 5. Begg's funnel plot did not

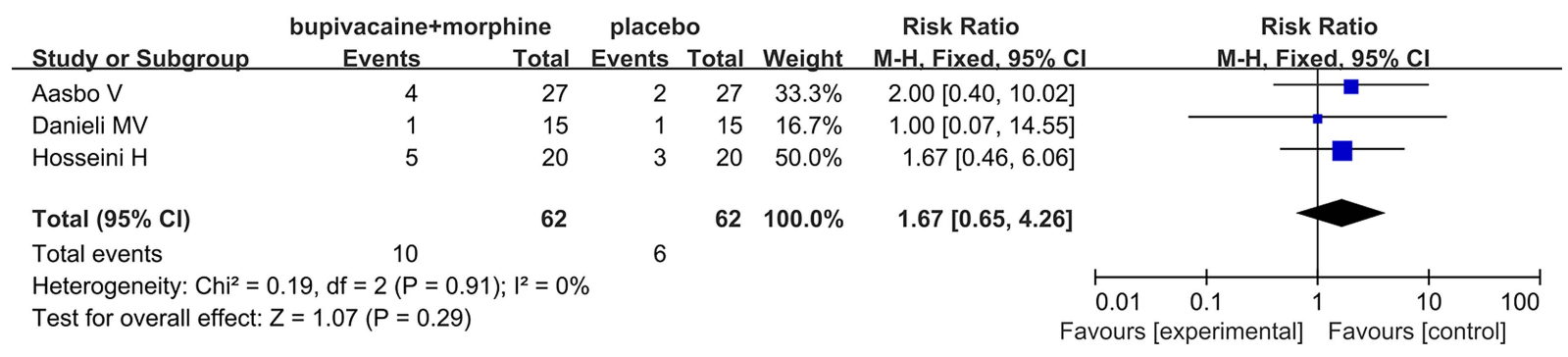

Figure 5 Forest plot of time to first analgesia request. 
show any substantial asymmetry, and Begg's rank correlation test did not indicate publication bias among the included studies $(\mathrm{p}=1.000)$.

\section{Side effects}

Three articles ${ }^{11} 12{ }^{21}$ evaluated side effects including nausea, vomiting, headache, pruritus and respiratory depression. Pooled data analysis revealed that there was no significant difference in side effects between the bupivacaine plus morphine group and the placebo group (RR 1.67; 95\% CI 0.65 to 4.26; $\mathrm{p}=0.29$ ). No substantial heterogeneity was observed $\left(\mathrm{I}^{2}=0 \% ; \mathrm{p}=0.91\right)$. The results are presented in figure 6. Begg's funnel plot did not show any substantial asymmetry, and Begg's rank correlation test did not indicate publication bias among the included studies $(p=1.000)$.
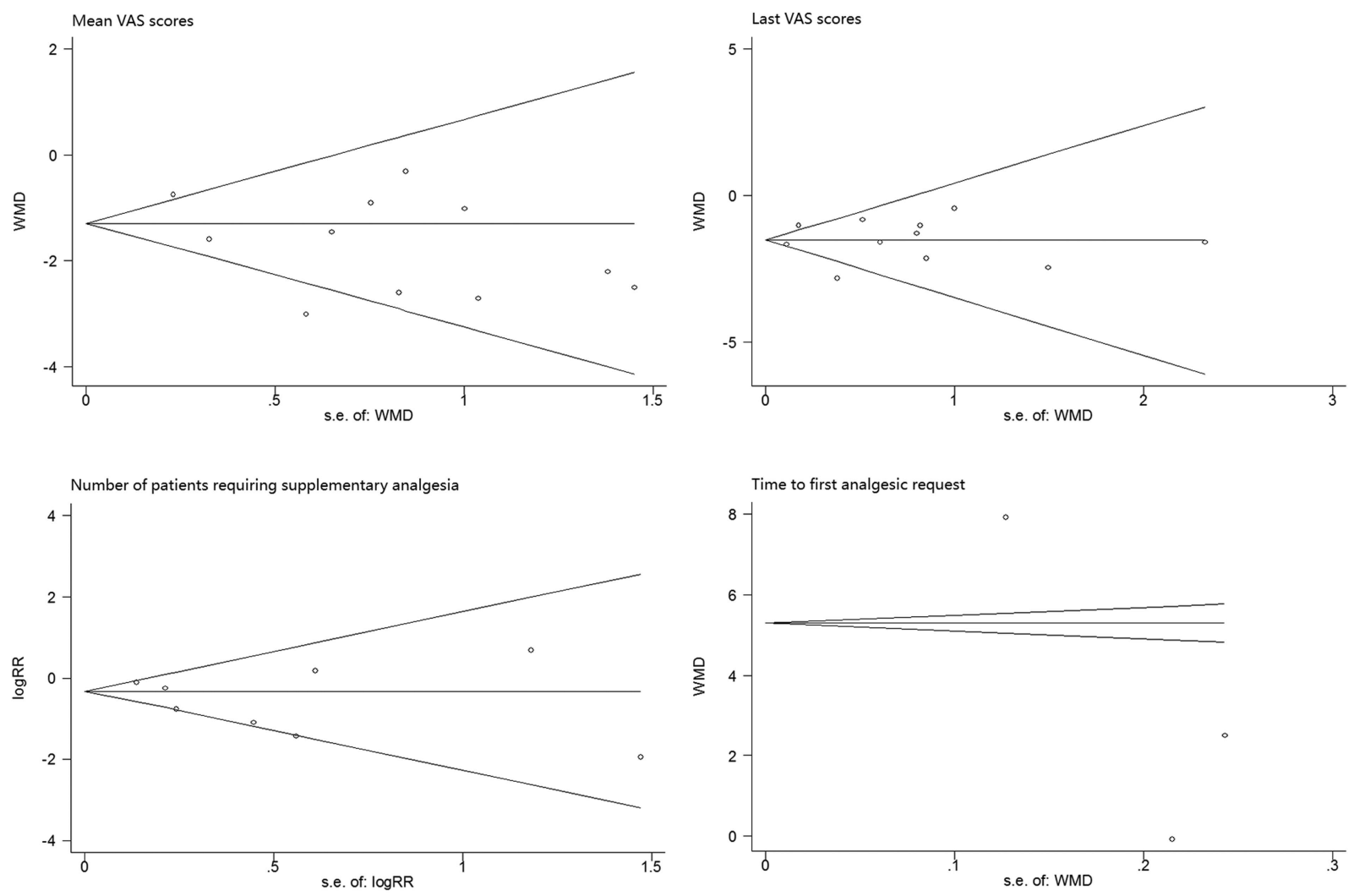

\section{DISCUSSION}

This quantitative meta-analysis involving 12 RCTs $^{11-22}$ showed that the combination therapy of single-dose IA bupivacaine and morphine is effective for pain relief after knee arthroscopic surgery. There was no significant difference between the two groups in terms of side effects.

Separate IA administration of bupivacaine or morphine alone has been reported to provide good postoperative analgesia after arthroscopic knee surgery. ${ }^{27-29}$ Eroglu et $a \ell^{30}$ further demonstrated the efficacy and safety of low-dose IA bupivacaine and morphine for spinal anaesthesia in outpatients after knee arthroscopic surgery. However, the efficacy and safety of combination therapy with IA bupivacaine and morphine remain controversial. This meta-analysis suggests that the administration of single-dose IA bupivacaine plus morphine is
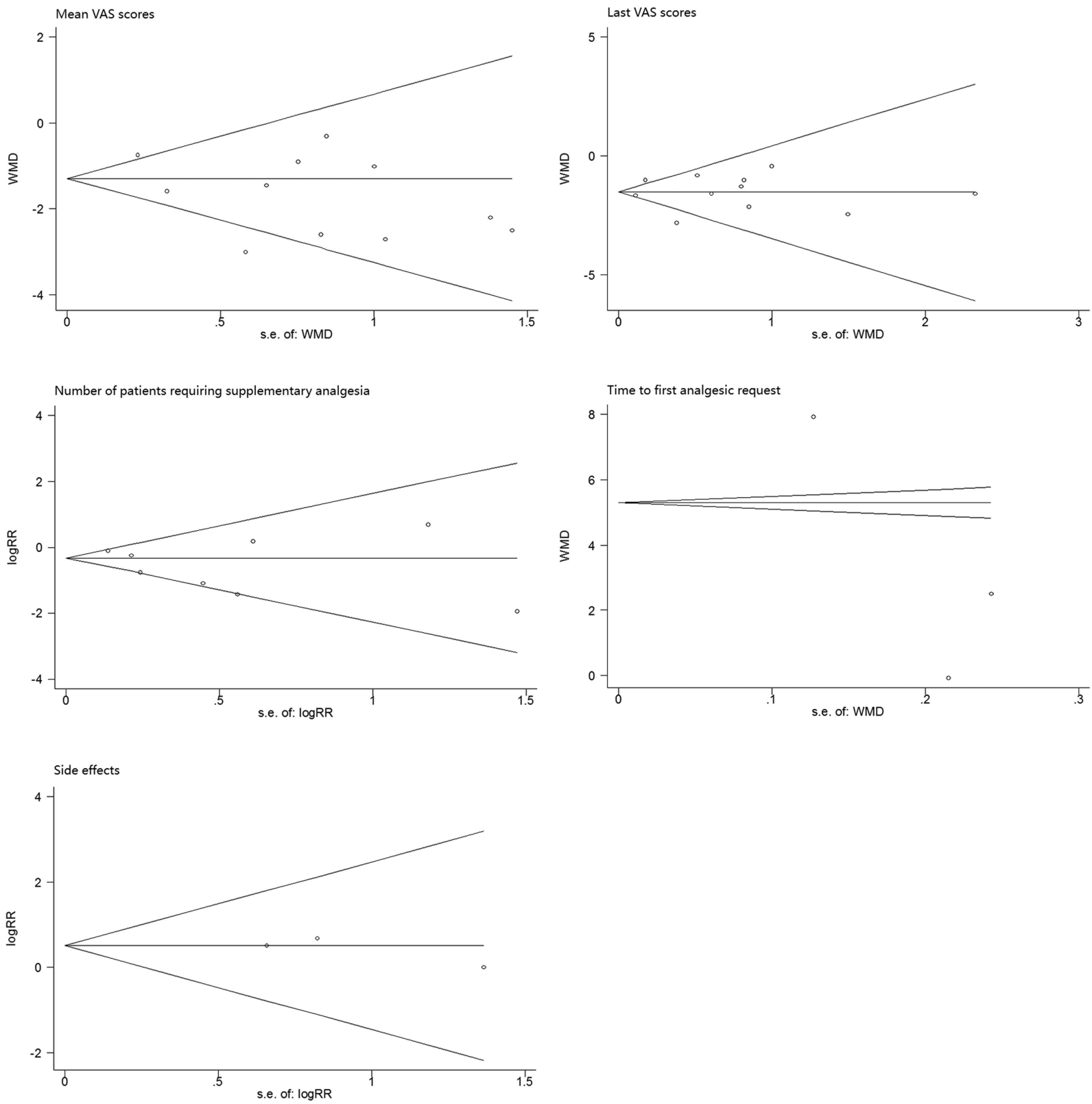

Figure 6 Forest plot of side effects. 
effective for pain relief after knee arthroscopic surgery, while its short-term side effects are similar to those of saline placebo.

The results described above are supported by some studies ${ }^{11-19}$ but not by others. ${ }^{20-22}$ The conflicting findings may be due to various factors. Ruwe $e t a l^{31}$ suggested that patients with preoperative pain were more likely to experience postoperative pain, so they regarded preoperative pain as a significant variable. Epinephrine may be another confounding factor. Haynes et $a l^{32}$ reported that the addition of epinephrine could decrease the effectiveness of morphine in the combination group. However, Allen's study ${ }^{27}$ indicated that the addition of epinephrine did not weaken the analgesic effect of IA bupivacaine plus morphine, but could rather prolong the duration of analgesia. Furthermore, Reuben and Sklar ${ }^{33}$ suggested that inflammation at the site of surgical trauma would cause increased postoperative pain, but this was not considered in our study.

The findings of this meta-analysis suggest that there was no significant difference (WMD 3.46; 95\% CI -1.81 to $8.72 ; \mathrm{p}=0.20$ ) between the bupivacaine plus morphine group and the placebo group in terms of time to first analgesic request. However, McSwiney et $a \vec{l}^{3}$ reached an opposite conclusion. They considered that the combination therapy of single-dose IA bupivacaine plus morphine should provide longer duration of analgesia. However, the small number of studies included in their report may have influenced this finding.

In this meta-analysis, three studies ${ }^{11} 1221$ reported the rate of side effects in both the bupivacaine plus morphine group and the placebo group. Most of the included studies ${ }^{13}$ 14-20 22 suggested that side effects were infrequent, and there was no statistically significant difference between the two groups. However, it is worth noting that in none of the included studies was the observation period long enough to detect the important side effect of cartilage toxicity following IA bupivacaine or morphine. Some reports ${ }^{35-39}$ indicated that IA bupivacaine might cause cartilage toxicity, while other claimed that IA bupivacaine is safe. ${ }^{40-42}$ However, IA morphine appeared to be an effective and less toxic analgesic. ${ }^{43}{ }^{44}$ Therefore, we can only conclude that single-dose IA bupivacaine plus morphine after knee arthroscopic surgery is safe in the short term.

This meta-analysis has several strengths. First, all included studies adopted a randomised placebocontrolled design, which improves comparability between groups and reduces the risk of selection bias. Second, it provides a comprehensive report of the effects of single-dose IA bupivacaine plus morphine after knee arthroscopic surgery. Based on pooled evidence from 12 RCTs conducted in a wide range of geographical locations, with different patient characteristics, baseline illness status and ethnicity, the findings of this meta-analysis have sufficient external validity to be generalised to a broader population. Last, this is the first quantitative analysis to compare single-dose IA bupivacaine plus morphine with saline placebo after knee arthroscopic surgery. The findings are therefore more reliable than those of previous reviews and RCTs.

The limitations of this meta-analysis should also be acknowledged. First, some potentially relevant RCTs were excluded for reasons such as publication in a language other than English, non-availability of extractable data, and non-availability of the full text. Therefore, the statistical power of the tests was limited due to the relatively small number of studies available for analysis of each variable. Second, substantial heterogeneity was observed in the number of patients requiring supplementary analgesia and the time to first analgesic request. Various potential confounding factors, such as variable dosage of administered medications and different follow-up times, may have contributed to this heterogeneity. In particular, although there was no significant difference in the time to first analgesic request between the two groups, the result was not absolutely reliable because of the great heterogeneity among the three studies $^{11} 1621$ ( $\mathrm{I}^{2}=100 \%$; $\left.\mathrm{p}<0.001\right)$. Finally, observation periods were not long enough to determine if cartilage toxicity, an important side effect, was caused by IA bupivacaine or morphine.

\section{CONCLUSIONS}

In conclusion, this meta-analysis of RCTs suggests that the administration of single-dose IA bupivacaine plus morphine after knee arthroscopic surgery is effective for pain relief, and that its short-term side effects are similar to those of saline placebo.

Contributors G-hL, Y-IW and CZ selected the studies. G-hL wrote the article. Y-IW and CZ helped write the article. D-XX, YY, JW, TY and HL reviewed the manuscript. All authors contributed to the design of the study.

Funding This work was supported by the Hunan Provincial Innovation Foundation for Postgraduate (CX2014A005), the Fundamental Research Funds for the Central Universities of Central South University, the National Natural Science Foundation of China (Nos. 81201420, 81272034, 81472130), the Provincial Science Foundation of Hunan (No. 14JJ3032), the Scientific Research Project of the Development and Reform Commission of Hunan Province ([2013]1199), the Scientific Research Project of Science and Technology Office of Hunan Province (2013SK2018), and the Doctoral Scientific Fund Project of the Ministry of Education of China (20120162110036).

\section{Competing interests None declared}

Provenance and peer review Not commissioned; externally peer reviewed.

Data sharing statement Extra data can be accessed via the Dryad data repository at http://datadryad.org/ under doi:10.5061/dryad.rq38c.

Open Access This is an Open Access article distributed in accordance with the Creative Commons Attribution Non Commercial (CC BY-NC 4.0) license, which permits others to distribute, remix, adapt, build upon this work noncommercially, and license their derivative works on different terms, provided the original work is properly cited and the use is non-commercial. See: http:// creativecommons.org/licenses/by-nc/4.0/

\section{REFERENCES}

1. Alipour M, Tabari M, Farhadi-faz R, et al. Effect of dexmedetomidine on postoperative pain in knee arthroscopic surgery; a randomized controlled clinical trial. Arch Bone Joint Surg 2014;2:52-6. 
2. Solheim N, Rosseland LA, Stubhaug A. Intra-articular morphine $5 \mathrm{mg}$ after knee arthroscopy does not produce significant pain relief when administered to patients with moderate to severe pain via an intra-articular catheter. Reg Anesth Pain Med 2006;31:506-13.

3. Stein C, Comisel K, Haimerl E, et al. Analgesic effect of intraarticular morphine after arthroscopic knee surgery. $N$ Engl J Med 1991;325:1123-6.

4. Parikh TJ, Divecha V, Dalwadi D. Comparative study between epidural morphine and bupivacaine with epidural clonidine and bupivacaine for postoperative pain relief in abdominal surgeries. Anesth Essays Res 2015;9:28-33.

5. Kundu R, Baidya DK, Arora MK, et al. Caudal bupivacaine and morphine provides effective postoperative analgesia but does not prevent hemodynamic response to pneumoperitoneum for major laparoscopic surgeries in children. J Anesth 2015. Published Online First.

6. El Shamaa HA, Ibrahim M. A comparative study of the effect of caudal dexmedetomidine versus morphine added to bupivacaine in pediatric infra-umbilical surgery. Saudi $J$ Anaesth 2014; 8:155-60.

7. Sharma NR, Timalsena P. Intrathecal morphine in combination with bupivacaine: a comparative study following caesarean section. Nepal Med Coll J 2013;15:37-9.

8. O O, Smith LJ. A comparison of epidural analgesia provided by bupivacaine alone, bupivacaine+morphine, or bupivacaine +dexmedetomidine for pelvic orthopedic surgery in dogs. Vet Anaesth Analg 2013;40:527-36.

9. Mercanoğlu E, Alanoğlu Z, Ekmekci P, et al. Comparison of intravenous morphine, epidural morphine with/without bupivacaine or ropivacaine in post-thoracotomy pain management with patient controlled analgesia technique. Rev Bras Anestesiol 2013:63:213-19.

10. Apiliogullari S, Duman A, Gok F, et al. Efficacy of a low-dose spinal morphine with bupivacaine for postoperative analgesia in children undergoing hypospadias repair. Paediatr Anaesth 2009;19:1078-83.

11. Hosseini $\mathrm{H}$, Abrisham SMJ, Jomeh $\mathrm{H}$, et al. The comparison of intraarticular morphine-bupivacaine and tramadol-bupivacaine in postoperative analgesia after arthroscopic anterior cruciate ligament reconstruction. Knee Surg Sports Traumatol Arthrosc 2012;20:1839-44.

12. Danieli MV, Neto AC, Herrera PA. Intra-articular bupivacaine or bupivacaine and morphine after ACL reconstruction. Acta Ortop Bras 2012;20:258-61.

13. Goodwin RC, Amjadi F, Parker RD. Short-term analgesic effects of intra-articular injections after knee arthroscopy. Arthroscopy 2005;21:307-12.

14. Tetzlaff JE, Dilger JA, Abate J, et al. Preoperative intra-articular morphine and bupivacaine for pain control after outpatient arthroscopic anterior cruciate ligament reconstruction. Reg Anesth Pain Med 1999:24:220-4.

15. Gatt CJ Jr, Parker RD, Tetzlaff JE, et al. Preemptive analgesia: its role and efficacy in anterior cruciate ligament reconstruction. Am J Sports Med 1998:26:524-9.

16. De Andres J, Valia JC, Barrera L, et al. Intra-articular analgesia after arthroscopic knee surgery: comparison of three different regimens. Eur J Anaesthesiol 1998:15:10-15.

17. Brandsson S, Rydgren B, Hedner T, et al. Postoperative analgesic effects of an external cooling system and intra-articular bupivacaine/ morphine after arthroscopic cruciate ligament surgery. Knee Surg Sports Traumatol Arthrosc 1996;4:200-5.

18. Karlsson J, Rydgren B, Eriksson B, et al. Postoperative analgesic effects of intra-articular bupivacaine and morphine after arthroscopic cruciate ligament surgery. Knee Surg Sports Traumatol Arthrosc 1995;3:55-9.

19. Joshi GP, McCarroll SM, O'Brien TM, et al. Intraarticular analgesia following knee arthroscopy. Anesth Analg 1993;76:333-6.

20. Denti M, Randelli P, Bigoni M, et al. Pre- and postoperative intra-articular analgesia for arthroscopic surgery of the knee and arthroscopy-assisted anterior cruciate ligament reconstruction. A double-blind randomized, prospective study. Knee Surg Sports Traumatol Arthrosc 1997;5:206-12.

21. Aasbo V, Raeder JC, Grogaard B, et al. No additional analgesic effect of intra-articular morphine or bupivacaine compared with placebo after elective knee arthroscopy. Acta Anaesthesiol Scand 1996;40:585-8

22. Bjornsson A, Gupta A, Vegfors $M$, et al. Intraarticular morphine for postoperative analgesia following knee arthroscopy. Reg Anesth 1994;19:104-8

23. Liberati A, Altman DG, Tetzlaff $J$, et al. The PRISMA statement for reporting systematic reviews and meta-analyses of studies that evaluate health care interventions: explanation and elaboration. $J$ Clin Epidemiol 2009;62:e1-e34.

24. Elia N, Tramer MR. Ketamine and postoperative pain-a quantitative systematic review of randomised trials. Pain 2005;113:61-70.

25. Jadad AR, Moore RA, Carroll D, et al. Assessing the quality of reports of randomized clinical trials: is blinding necessary? Control Clin Trials 1996;17:1-12.

26. Begg CB, Mazumdar M. Operating characteristics of a rank correlation test for publication bias. Biometrics 1994;50:1088-101.

27. Allen GC, St Amand MA, Lui AC, et al. Postarthroscopy analgesia with intraarticular bupivacaine/morphine. A randomized clinical trial. Anesthesiology 1993;3:475-80.

28. Heard SO, Edwards WT, Ferrari D, et al. Analgesic effect of intraarticular bupivacaine or morphine after arthroscopic knee surgery: a randomized, prospective, double-blind study. Anesth Analg 1992;6:822-6.

29. Khoury GF, Chen AC, Garland DE, et al. Intrarticular morphine, bupivacaine, and morphine/bupivacaine for pain control after knee videoarthroscopy. Anesthesiology 1992;2:263-6.

30. Eroglu A, Saracoglu S, Erturk E, et al. A comparison of intraarticular morphine and bupivacaine for pain control and outpatient status after an arthroscopic knee surgery under a low dose of spinal anaesthesia. Knee Surg Sports Traumatol Arthrosc 2010;18:1487-95.

31. Ruwe PA, Klein I, Shields CL. The effect of intraarticular injection of morphine and bupivacaine on postarthroscopic pain control. $\mathrm{Am} \mathrm{J}$ Sports Med 1995;23:59-64.

32. Haynes TK, Appadurai IR, Power I, et al. Intra-articular morphine and bupivacaine analgesia after arthroscopic knee surgery. Anaesthesia 1994:49:54-6.

33. Reuben SS, Sklar J. Pain management in patients who undergo outpatient arthroscopic surgery of the knee. J Bone Joint Surg Am 2000;82:1754-66.

34. McSwiney MM, Joshi GP, Kenny P, et al. Analgesia following arthroscopic knee surgery. A controlled study of intra-articular morphine, bupivacaine or both combined. Anaesth Intens Care 1993;21:201-3.

35. Chu CR, Coyle $\mathrm{CH}$, Chu $\mathrm{CT}$, et al. In vivo effects of single intra-articular injection of $0.5 \%$ bupivacaine on articular cartilage. J Bone Joint Surg Am 2010;92:599-608.

36. Chu CR, Izzo NJ, Coyle $\mathrm{CH}$, et al. The in vitro effects of bupivacaine on articular chondrocytes. $J$ Bone Joint Surg Br 2008:90:814-20.

37. Grishko V, Xu M, Wilson G, et al. Apoptosis and mitochondrial dysfunction in human chondrocytes following exposure to lidocaine, bupivacaine, and ropivacaine. J Bone Joint Surg Am 2010;92:609-18.

38. Piper SL, Kim HT. Comparison of ropivacaine and bupivacaine toxicity in human articular chondrocytes. J Bone Joint Surg Am 2008;90:986-91.

39. Piper SL, Kramer JD, Kim HT, et al. Effects of local anesthetics on articular cartilage. Am J Sports Med 2011;39:2245-53.

40. Dragoo JL, Braun HJ, Kim HJ, et al. The in vitro chondrotoxicity of single-dose local anesthetics. Am J Sports Med 2012;40:794-9.

41. Dragoo JL, Korotkova T, Kanwar R, et al. The effect of local anesthetics administered via pain pump on chondrocyte viability. Am J Sports Med 2008;36:1484-8.

42. Dragoo JL, Korotkova T, Kim HJ, et al. Chondrotoxicity of low pH, epinephrine, and preservatives found in local anesthetics containing epinephrine. Am J Sports Med 2010;38:1154-9.

43. Jaureguito JW, Wilcox JF, Thisted RA, et al. The effects of morphine on human articular cartilage of the knee: an in vitro study. Arthroscopy 2002;18:631-6.

44. Anz A, Smith MJ, Stoker A, et al. The effect of bupivacaine and morphine in a coculture model of diarthrodial joints. Arthroscopy 2009;25:225-31. 